\title{
Densification of Corncobs Using Algae as a Binder
}

\author{
Pimpond Piboon$^{1}$, Nakorn Tippayawong ${ }^{1 *}$, and Thanasit Wongsiriamnuay ${ }^{2}$ \\ ${ }^{1}$ Department of Mechanical Engineering, Faculty of Engineering, Chiang Mai \\ University, Chiang Mai 50200, Thailand \\ ${ }^{2}$ Faculty of Engineering and Agro-Industry, Maejo University, Chiang Mai 50290, \\ Thailand \\ *Corresponding author. Email: n.tippayawong@yahoo.com \\ https://doi.org/10.12982/CMUJNS.2017.0014
}

\begin{abstract}
Corn residues are abundantly available, but utilizing this potential biomass energy source is limited by their low density and non-uniform physical characteristics. Densification may be used to solve this problem. Many studies have used high temperature and pressure to compress biomass materials into pellets, as well as expensive additives to produce high-quality pellets. In this study, we investigated whether moderate temperature and pressure with a binding agent from an inexpensive and environmentally friendly source offers an alternative solution. We used locally available algae (Spirogyra sp. and Chara sp.) as a binding agent for densification of corncobs and studied the effects of pressure (100-200 MPa) and algae-to-biomass ratio $(10-40 \% \mathrm{w} / \mathrm{w})$, at a fixed die temperature of $30^{\circ} \mathrm{C}$, on pellet characteristics. We found that algae can be successfully used as binder for densification of biomass. Using the algae at $20 \% \mathrm{w} / \mathrm{w}$ or less with an applied pressure of 150-200 MPa improved the relaxed density of the pellets by 250-285\%, higher than the bulk density of the original corncobs before compaction, with energy density of 12-14 $\mathrm{GJ} / \mathrm{m}^{3}$.
\end{abstract}

Keywords: Agricultural residues, Biomass, Pelletization, Renewable energy

\section{INTRODUCTION}

Northern Thailand produces the most corn in the country, with Chiang Mai Province one of the biggest producers, with over 128,000 tons annual output in 2014 (Office of Agricultural Economics, 2014). After harvesting, large amounts of corn residue are usually abandoned in the fields and subsequently burned as a method of disposal. Air pollutants, especially smoke, from burning these residues adversely affect public health and the environment.

Potentially, around 520 TJ of biomass energy can be derived from these corn residues in Chiang Mai Province and surrounding areas. These agricultural residues may be utilized for energy via physical or thermochemical conversion routes to help reduce these problems (Wongsiriamnuay et al., 2013; Auprakul et al., 2014; Sittisun et al., 2015; Wongsiriamnuay and Tippayawong, 2015; 
Jaroenkhasemmeesuk and Tippayawong, 2015; 2016). Their energy potential is obvious, but their use is limited due mainly to low density and non-uniformity of their physical characteristics.

Densification is a physical conversion method to improve the quality of voluminous materials by compacting them into pellets or briquettes (Kaliyan and Morey, 2010). The technique is sufficiently simple and straightforward. Agricultural residues are usually pelletized using high temperature and pressure, and may require expensive additives to produce high-quality pellets (Kaliyan and Morey, 2009a; 2009b; Wongsiriamnuay and Tippayawong, 2015); this can be expensive. Moderate temperature and pressure with a binding agent from an inexpensive and environmentally friendly source offers an alternative solution. A suitable binder may be obtained from other potential biomass materials, with algal biomass a promising candidate. It is readily available from biological wastewater treatment and natural surface water sources. Various species of algae have been shown to be potentially good binding agents (Jiang et al., 2014; Thapa et al., 2014).

This study used a mixture of local algae (Spirogyra sp. and Chara sp.) as a binding agent and investigated the changes in the physico-chemical properties of the resultant densified corncobs. The effects of pressure (100-200 MPa) and algae-to-corncob ratio (10-40\%) on the pellet densities and energetic content were examined, at a fixed die temperature of $30^{\circ} \mathrm{C}$.

\section{MATERIALS AND METHODS}

\section{Material preparation}

Corncobs and algae (Spirogyra sp. and Chara sp.) were collected locally from fields and canals around Chiang Mai, Thailand. They were dried in the sun for at least one week. Afterwards, the corn residues were crushed using a hammer mill, graded into a size range of 0.1-0.6 $\mathrm{mm}$; the algae was ground into a size range of 0.1-0.3 mm (Figure 1). To blend well, the sizes need to be similar. The feed inputs were mixed thoroughly at ratios from $90 \%$ corncobs and $10 \%$ algae (C90A10) to $60 \%$ corncobs and $40 \%$ algae (C60A40) by weight.

\section{Densification experiment}

For each mix, the blended feed was loaded into and compressed using a compacting apparatus, shown in Figure 2 (Wongsiriamnuay and Tippayawong, 2015). Each pellet contained around $2 \mathrm{~g}$ of overall mass. The densifier consisted of a piston ( $0.9 \mathrm{~cm}$ diameter and $10 \mathrm{~cm}$ long) and a closed-end die composed of a cylinder ( $0.9 \mathrm{~cm}$ diameter and $7 \mathrm{~cm}$ long) and a base. A $450 \mathrm{~W}$ heater was mounted to the densifier to heat the die and biomass materials during compaction. A universal testing machine was used to apply known loads. The die temperature was fixed at $30^{\circ} \mathrm{C}$, with compaction pressures of 100,150 , and $200 \mathrm{MPa}$. Each condition was repeated at least six times. The applied pressure was measured by a pressure gauge. The temperature was measured by a thermocouple and controlled by a digital controller. Each pellet was held for $10 \mathrm{~s}$ to counter the spring-back effect (Mani et al., 2006). 

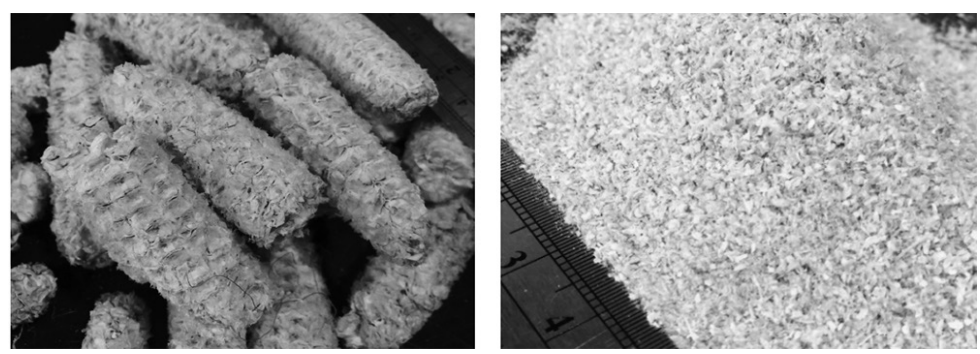

(a) Corncobs
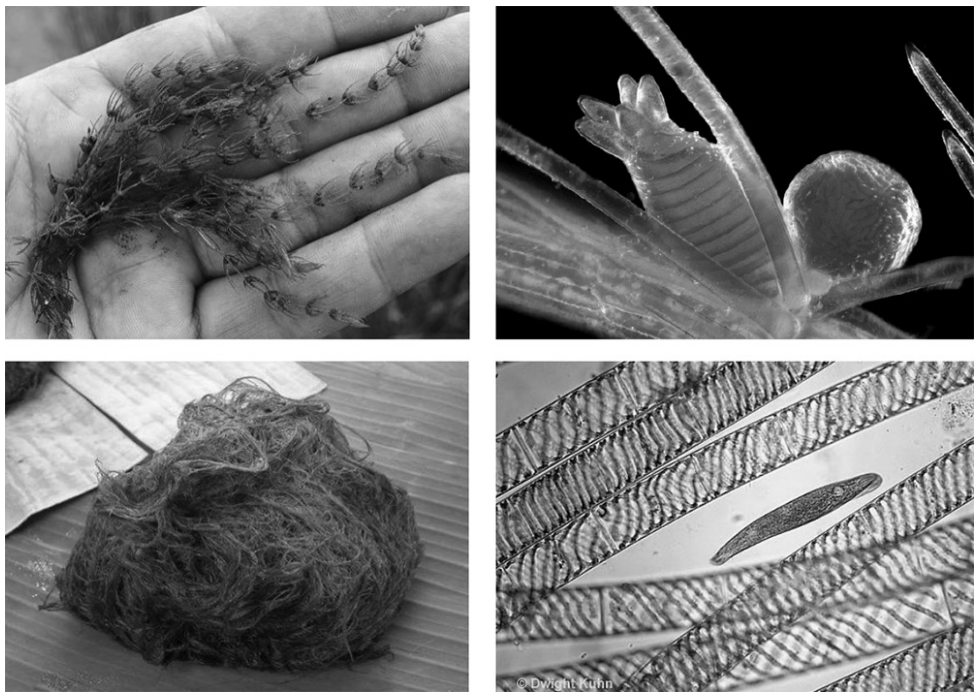

(b) Algae (Chara sp. \& Spirogyra sp.)

Figure 1. Biomass and binder samples.

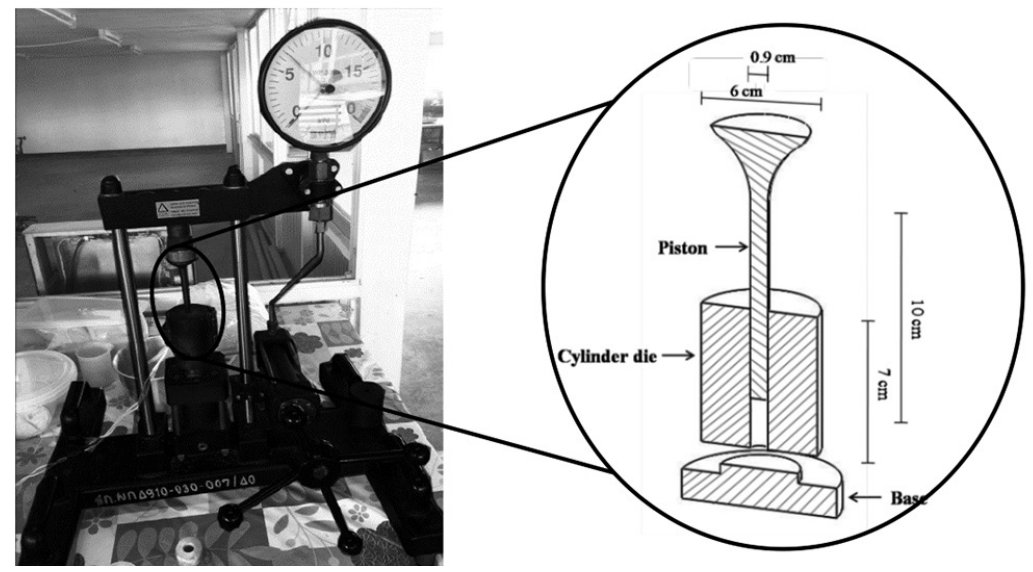

Figure 2. The compacting apparatus. 
After compression, the compact density was determined immediately using equation 1 . Then the pellets were stored in an airtight bag at room temperature for one week. The relaxed density was subsequently evaluated using equation 2 .

$$
\begin{aligned}
& \text { Compact density }=\frac{\mathrm{m}}{\mathrm{V}_{\mathrm{c}}} \\
& \text { Relaxed density }=\frac{\mathrm{m}}{\mathrm{V}_{\mathrm{r}}}
\end{aligned}
$$

where $\mathrm{m}$ is the mass of the pellet $(\mathrm{kg}), \mathrm{V}_{\mathrm{c}}$ is the volume of the pellet immediately after compaction $\left(\mathrm{m}^{3}\right)$, and $\mathrm{V}_{\mathrm{r}}$ is the volume of the pellet after storage for one week $\left(\mathrm{m}^{3}\right)$.

Moisture content and bulk density of the materials were determined following the ASAE 358.2 and ASTM E 873-82 standards, respectively. Calorific value was measured using a bomb calorimeter following the BS EN 14918 standard.

\section{RESULTS}

\section{Physical appearance}

The moisture content on a dry basis of the corncobs and algae were $9 \pm 0.2$ and $6 \pm 0.2 \%$, respectively, and bulk densities of corncobs and algae were $230 \pm 10.1$ and $660 \pm 11.2 \mathrm{~kg} / \mathrm{m}^{3}$, respectively. Figure 3 shows the appearance of the pellets after densification and storage for one week. The pure corncob pellets (C100A0) were loose and broken, compared to those with algae as binder. Pure algae pellets (C0A100) appeared very tight, and their physical appearance did not vary much with applied pressures. Increasing the proportion of algae was observed to improve

\begin{tabular}{|c|c|c|c|c|c|c|}
\hline $\begin{array}{l}\text { Ratio } \\
\text { Pressure } \\
(\mathrm{MPa})\end{array}$ & $\mathrm{C} 100 \mathrm{~A} 0$ & C90A 10 & $\mathrm{C} 80 \mathrm{~A} 20$ & $\mathrm{C} 70 \mathrm{~A} 30$ & $\mathrm{C} 60 \mathrm{~A} 40$ & C0A 100 \\
\hline 100 & & & 永 & & & \\
\hline 150 & & & & 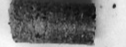 & & \\
\hline 200 & & & & & & \\
\hline
\end{tabular}
the firmness of the pellets.

Figure 3. Pellets after compression at $30^{\circ} \mathrm{C}$, and storage for one week. 


\section{Compact and relaxed density}

Pellet densities are shown in Figures 4 (a) to (f). Increasing pressure and algae in the mixture resulted in increasing pellet densities. The compact density, or density of the pellets immediately after compaction, of the pure corncob pellets and algae pellets were $246-276$ and $118-147 \%$ higher than the original bulk density of the corncobs and algae before compaction. When algae was blended with corncobs at $10,20,30$, and $40 \%$ by weight, the compact density of the resulting pellets increased by $251-301,259-320,290-337$, and 298-364\%, respectively. Relaxed density, or density of the pellets after storage, of the pure corncob and algae pellets and the mixed pellets were less than the compact density by $9-12$ and 1-4 for the pure pellets and 10-13, 9-13, 6-10, and 8-9\% for the mixed pellets, respectively.

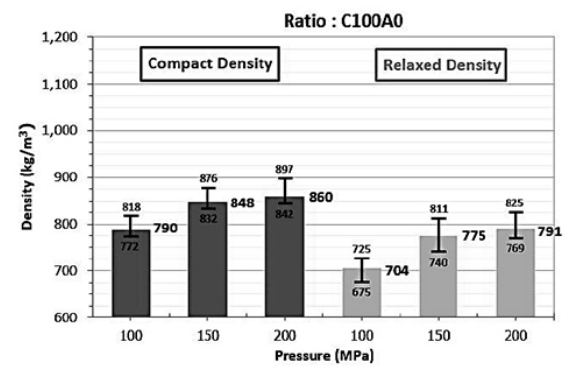

(a) Corncob 100\%: Algae 0\% (w/w)

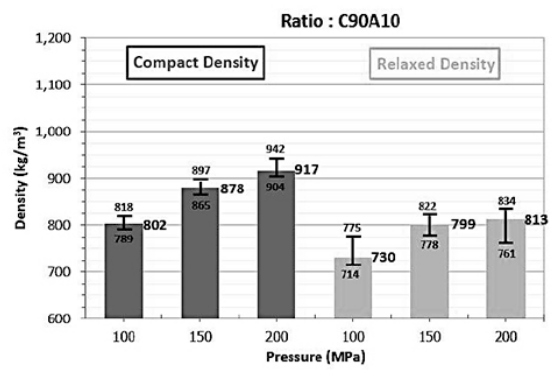

(c) Corncob 90\%: Algae 10\% (w/w)

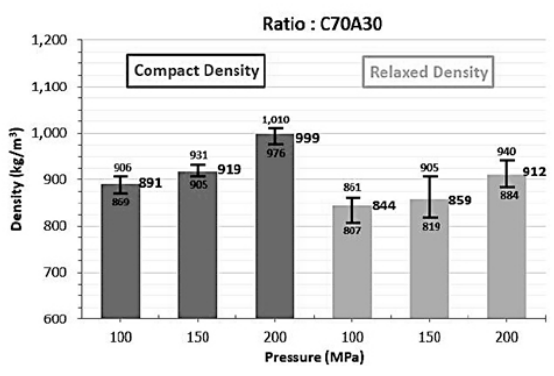

(e) Corncob 70\%: Algae 30\% (w/w)

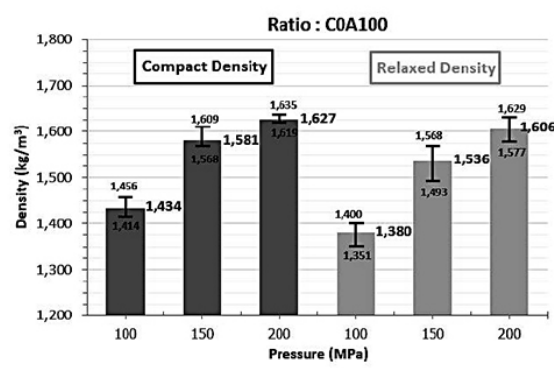

(b) Corncob 0\%: Algae 100\% (w/w)

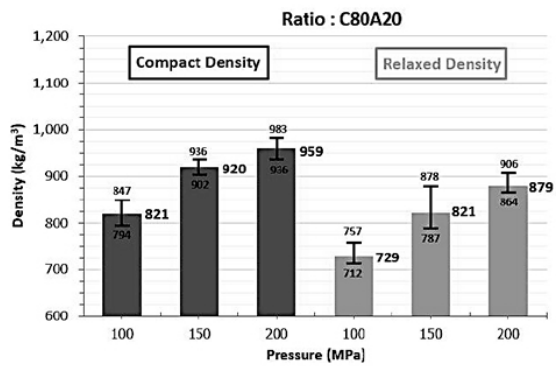

(d) Corncob $80 \%:$ Algae 20\% (w/w)

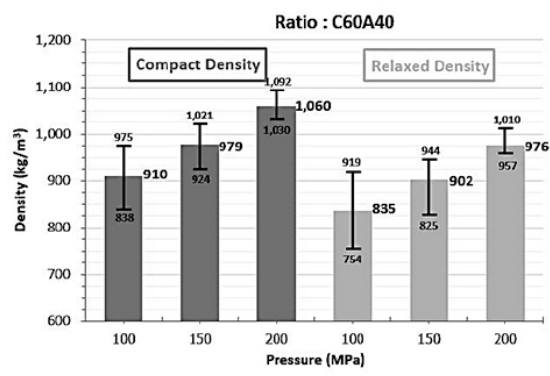

(f) Corncob 60\% : Algae 40\% (w/w)

Figure 4. Variation in pellet densities with applied pressure and mixture ratio. 


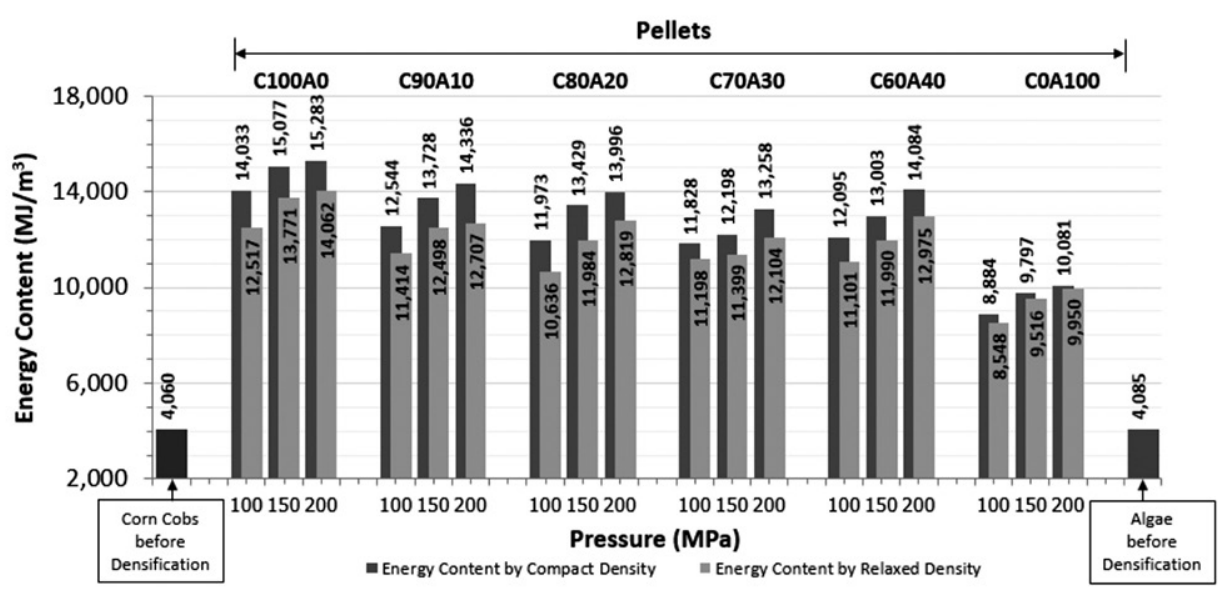

Figure 5. Variation in energetic density of the pellets with applied pressure and mixture ratio.

\section{Energy density}

The heating value of the algae used was 5.0-7.4 MJ/kg; this was much lower than the corncobs (17.1-18.5 MJ/kg). The energy density $\left(\mathrm{MJ} / \mathrm{m}^{3}\right)$, defined as the product of the heating value $(\mathrm{MJ} / \mathrm{kg})$ and density $\left(\mathrm{kg} / \mathrm{m}^{3}\right)$, was used to select the appropriate ratio of corncobs to algae. The average energy density of the original corncobs and algae before densification were both about $4.1 \mathrm{GJ} / \mathrm{m}^{3}$. The average energy content of the pure corncob and algae pellets were 12.5-15.3 and 8.6-10.1 $\mathrm{GJ} / \mathrm{m}^{3}$, respectively (Figure 5). The energy density of the mixed pellets was at $11-14 \mathrm{GJ} / \mathrm{m}^{3}$. The energy density of the mixed pellets was $2.7-3.5$ times higher than the original materials before compaction.

\section{DISCUSSION}

Using a fixed die temperature, this study varied the compression pressure and amount of binding agent used to produce pellets. Increasing pressure forced the closed solid particles to adhere to or fold into each other, resulting in improved attraction forces between the solid particles or interlocking bonds; this was evident in the physical appearance of the pellets (Kaliyan and Morey, 2009b; Wongsiriamnuay and Tippayawong, 2015). This, in turn, led to tighter corncob and mixed-biomass pellets. In contrast, the pure algae pellets did not exhibit a similar behavior, as pure algae is comprised of smaller particles with different constituents, such as starch, protein, lignin, and fiber (Thapa et al., 2014).

Increasing pressure increased the density of the pellets. Compact density was always higher than relaxed density. The addition of algae as a binding agent improved pellet density, but lowered heating values. Thapa et al. (2014) reported similar findings. Mixing algae with the corncobs also reduced the energy density, although the difference was moderate. 
This study has shown that algae is an effective binder for increasing the densities of corn residues at moderate pressures and low die temperature. Densified biomass appeared to be durable. Within the experimental conditions tested in this research, mixing algae at $20 \%$ by weight with an applied pressure of $150-200 \mathrm{MPa}$ was sufficient to improve the quality of the corncob pellets, without a significant reduction in their energy content.

Other parameters, such as energy consumption and durability of the resultant pellets, should be further studied to determine the optimum production conditions. Nonetheless, the conditions studied here offered a decent and alternative utilization of corn residues that could potentially be applied to other agricultural residues, as well.

\section{ACKNOWLEDGEMENTS}

Chiang Mai University supported this study. We would like to thank Dr. Yuwalee Unpaprom and Maejo University for providing the algae samples and some of the laboratory facilities.

\section{REFERENCES}

Auprakul, U., Promwungkwa, A., and Tippayawong, N. 2014. Densified fuels from mixed plastic wastes and corn stover. Advanced Materials Research. 931-932: 1117-1121.

Jaroenkhasemmeesuk, C., and Tippayawong, N. 2015. Technical and economic analysis of a biomass pyrolysis plant. Energy Procedia. 79: 950-955.

Jaroenkhasemmeesuk, C., and Tippayawong, N. 2016. Thermal degradation kinetics of sawdust under intermediate heating rates. Applied Thermal Engineering. 103: 170-176.

Jiang, L., Liang, J., Yuan, X., Li, H., Li, C., Xiao, Z., Huang, H., Wang, H., and Zeng, G. 2014. Co-pelletization of sewage sludge and biomass: the density and hardness of pellet. Bioresource Technology. 166: 435-443.

Kaliyan, N., and Morey, R.V. 2009a. Densification characteristics of corn stover and switchgrass. Transactions of American Society of Agricultural and Biological Engineers. 52: 907-920.

Kaliyan, N., and Morey, R.V. 2009b. Factors affecting strength and durability of densified biomass products. Biomass \& Bioenergy. 33: 337-359.

Kaliyan, N., and Morey, R.V. 2010. Densification characteristics of corn cobs. Fuel Processing Technology. 91: 559-565.

Mani, S., Tabil, L.G., and Sokhansanj, S. 2006. Effects of compressive force, particle size and moisture content on mechanical properties of biomass pellets from grasses. Biomass \& Bioenergy. 30: 648-654.

Office of Agricultural Economics. 2014. Agricultural statistics of Thailand. Ministry of Agriculture and Cooperatives. Available online at http://www. oae.go.th/, accessed on June 2016. 
Sittisun, P., Tippayawong, N., and Wattanasiriwech, D. 2015. Thermal degradation characteristics and kinetics of oxy combustion of corn residues. Advances in Materials Science \& Engineering. Article ID 304395, 2015, 1-8.

Thapa, S., Johnson, D.B., Liu, P.P., and Canam, T. 2014. Algal biomass as a binding agent for the densification of Miscanthus. Waste \& Biomass Valorization. 6: 91-95.

Wongsiriamnuay, T., Kannang, N., and Tippayawong, N. 2013. Effect of operating conditions on catalytic gasification of bamboo in a fluidized bed. International Journal of Chemical Engineering. Article ID 297941, 2013: 1-9.

Wongsiriamnuay, T., and Tippayawong, N. 2015. Effect of densification parameters on the properties of maize residue pellets. Biosystems Engineering. 139: $111-120$. 